\title{
Snodgrass Tubularized Incised Plate Urethroplasty for Distal and Midpenile Hypospadias
}

\author{
Thapa $\mathrm{B}^{1}$, Pun $\mathrm{M}^{2}$
}

\begin{abstract}
Introduction: Despite hundreds of repair techniques for hypospadias, the introduction of tubularized incised plate urethroplasty (TIP) by Warren T. Snodgrass has become popular because of good functional and cosmetic outcome. The objective of this study was to share our experience of Snodgrass tubularized incised plate (TIP) urethroplasty for the repair of distal and mid-penile hypospadias. Materials and Methods: This prospective study was carried out for a period of 24 months. It included 46 male patients with the mean age of 4.1 years ( 18 months to 10 years). Proximal hypospadias and those distal with moderate to severe chordee were excluded. All cases underwent TIP urethroplasty as described by Snodgrass and the neourethra was covered by single or double layer of dorsal prepucial layer. The results were analyzed on the basis of duration of surgery, types of postoperative complications like urethrocutaneous fistula, meatal stenosis and wound dehiscence. Functional results assessed with ease of voiding, force and direction of urinary stream and cosmetic with external look of penis. Results: The overall complication rate requiring surgical intervention was 8 (17.3\%). Mean duration of surgery was 66 minutes (60-80 minutes). Urethrocutaneous fistula occurred in 5 (10.8\%), meatal stenosis in 1 (2.1\%) and wound dehiscence in 2 (4.3\%) patient. The cosmetic appearance was excellent in all patients involved in this study except 2 cases of wound dehiscence. All of them had vertically oriented slit like meatus with straight urinary stream. Conclusion: Tubularized incised plate urethroplasty gives good functional and excellent cosmetic results with low rate of complications in distal and mid-penile hypospadias.
\end{abstract}

Key Words: Hypospadias, Tubularized incised plate urethroplasty, Snodgrass.

\section{Introduction}

Lypospadias is one of the most common congenital anomaly of external genitalia in males occurring in approximately 1 in 200 300 live birth. The abnormal urethral opening can be anywhere along the ventral side of penile shaft and down to the perineum. In over $80 \%$ of cases, the meatus is located distal to the midshaft ${ }^{1,2}$.
'Dr. Bijay Thapa, MBBS, MS, Consultant Paediatric Surgeon, ${ }^{2} \mathrm{Dr}$. Madhusudan Pun, MBBS, MS, Head of Department and Consultant Paediatric Surgeon. Both from the department of Paediatric Surgery, Kanti Children's Hospital, Maharajgunj, Kathmandu, Nepal.

\section{Address for correspondence \\ Dr. Bijay Thapa \\ Consultant Paediatric Surgeon \\ Kanti Children's Hospital \\ Kathmandu, Nepal. \\ Tel: 977-9851029644 \\ E-mail: bijaytapa@hotmail.com}

\section{How to cite}

Thapa B, Pun M. Snodgrass Tubularized Incised Plate Urethroplasty for Distal and Midpenile Hypospadias. J Nepal Paediatr Soc 2014;34(1):2933.

doi: http://dx.doi.org/10.3126/jnps.v34i1.8692

This work is licensed under a Creative Commons Attribution 3.0 License.

(c) (i)

There are over 200 procedures described in literature about hypospadias surgery. The ultimate goal of hypospadias repair is to achieve a functional penis with normal looking cosmetically ${ }^{3,4}$. Tubularized Incised plate (TIP) urethroplasty by Snodgrass in 1994 has gained popularity and revolutionized the management of different types of hypospadias including proximal hypospadias and in re-operative cases. TIP procedure is technically easy giving a normal looking vertical slit like meatus with low complications like urethrocutaneous 
fistula, meatal stenosis ${ }^{5,6,7}$. The purpose of our study was to share our experience with TIP urethroplasty in the management of distal hypospadias.

\section{Materials and Methods}

A total of 46 male children 18 months to 10 years age with penile hypospadias were included in this study from January 2011 to January 2013 in Kanti Children's Hospital and BP Smriti Hospital. Only distal and mid penile hypospadias with good and wide urethral plate were included. All children underwent tubularized incised plate urethroplasty described by Snodgrass. Hypospadias with moderate to severe chordee were excluded.

Table 1: Types of hypospadias in children $(n=46)$ who underwent Snodgrass Tubularized Incised Plate urethroplasty

\begin{tabular}{|c|c|}
\hline Types & No of patients (n) \\
\hline Coronal & $6(13.04 \%)$ \\
\hline Sub coronal & $17(36.95 \%)$ \\
\hline Distal shaft & $15(32.60 \%)$ \\
\hline Mid shaft & $8(17.39 \%)$ \\
\hline Total & $\mathbf{4 6 ( 1 0 0 \% )}$ \\
\hline
\end{tabular}

Table 2: Age distribution of patients $(n=46)$ with hypospadias who underwent Snodgrass Tubularized Incised Plate urethroplasty

\begin{tabular}{|c|c|}
\hline Range & No. of patients \\
\hline 0-2 years & $10(21.73 \%)$ \\
\hline 2-4 years & $20(43.47 \%)$ \\
\hline 4-6 years & $8(17.39 \%)$ \\
\hline 6-8 years & $5(10.86 \%)$ \\
\hline 8- 10 years & $3(6.52 \%)$ \\
\hline Total & $\mathbf{4 6 ( 1 0 0 \% )}$ \\
\hline
\end{tabular}

All the patients did all basic investigations like total blood count, urea, creatinine, urine routine and culture and examined for any other associated anomalies of genito-urinary system by abdominal ultrasound. The operation was performed under general anesthesia along with caudal block. A stay suture was placed in glans to aid in the traction of the phallus. Eight to 10 French Foleys catheter were placed on the basis of patient age and size of phallus. Rubber tourniquet applied at the base of penis and released at 40 minutes interval. A U-shaped incision was made, extending along the edges of the urethral plate approximately 8-10 $\mathrm{mm}$ up to the glans and to the healthy skin $2 \mathrm{~mm}$ proximal to the meatus. The plate was freed on both side. Then an incision was added in midline of urethral plate from native meatus up to the glans. The urethral plate was tubularized over the catheter using 6-0 absorbable suture centisorb (poly glycolide-co-lactide) with running sub epithelial stitches. Neourtehra was then covered with one or two vascularised subcutaneous (dartos) flap those harvested from the dorsal prepuce. Glanuloplasty was done by closure of of glandular wings and the tip with neourethral plate. The granular wings, mucosal collar and ventral shaft skin were closed in the midline. A light compressive dressing was applied.

Intravenous third generation cephalosporin with $100 \mathrm{mg} / \mathrm{kg} /$ day in three divided doses were given for five days and changed to oral. Pain managed with intramuscular pethidine $1 \mathrm{mg} \mathrm{kg} /$ dose initially in addition with oral paracetamol (flexon). All cases had dressing opened on $3 \mathrm{rd}$ or $4^{\text {th }}$ postoperative day. Neosporin ointment was applied after the dressing was opened regularly. Foleys catheter was taken out on $8^{\text {th }}$ to $10^{\text {th }}$ postoperative days seeing the conditions of healing and patients discharged. Patients were informed for follow ups after two weeks of discharge to see the wound status and see the urinary stream and any other complication.

Each patient was assessed on the 8th-10th postoperative day after removal of the catheter and during their first follow-up on two weeks after discharge. Assessment was done on the basis complications like urethrocutaneous fistula, meatal stenosis, cosmetic look of penis and glans and urinary stream.

\section{Results}

Overall complications occurred in eight patients with the complication rate of $17.3 \%$. Five $(10.86 \%)$ cases had urethrocutaneous fistula. Out of 5 fistula cases, four urethrocutaneous fistula was seen after the catheter was removed and the remaining one had fistula after two weeks of discharge. Meatal stenosis occurred in one case. In one coronal and subcoronal hypospadias complete wound with glandular dehiscence was seen. Surgery time duration ranged from 60 minutes to 80 minutes with an average 66 minutes. Forty four(95\%) cases had a normally situated vertical slit like meatus and voided with a straight urinary stream except with two cases with wound dehicence. Meatus was almost at the tip of the glans penis with excellent cosmetic looking. 
Table 3: Postoperative results after Snodgrass Tubularized Incised Plate urethroplasty $(n=46)$

\begin{tabular}{|c|c|c|c|c|c|}
\hline $\begin{array}{c}\text { Types of } \\
\text { hypospadias }\end{array}$ & No. of pts & $\begin{array}{c}\text { Urethrocutaneous } \\
\text { Fistula }\end{array}$ & $\begin{array}{c}\text { Meatal } \\
\text { stenosis }\end{array}$ & $\begin{array}{c}\text { Wound } \\
\text { dehiscence }\end{array}$ & $\begin{array}{c}\text { Good cosmetic } \\
\text { appearance }\end{array}$ \\
\hline Coronal & 6 & 0 & 0 & 1 & 5 \\
\hline Sub coronal & 17 & 1 & 0 & 1 & 16 \\
\hline Distal shaft & 15 & 2 & 0 & 0 & 15 \\
\hline Mid shaft & 8 & 2 & 1 & 0 & 7 \\
\hline Total & $\mathbf{4 6 ( 1 0 0 \% )}$ & $\mathbf{5 ( 1 0 . 8 6 \% )}$ & $\mathbf{1 ~ ( 2 . 1 \% )}$ & $\mathbf{2 ~ ( 4 . 3 \% )}$ & $\mathbf{4 3}(\mathbf{9 3 . 4 \% )}$ \\
\hline
\end{tabular}

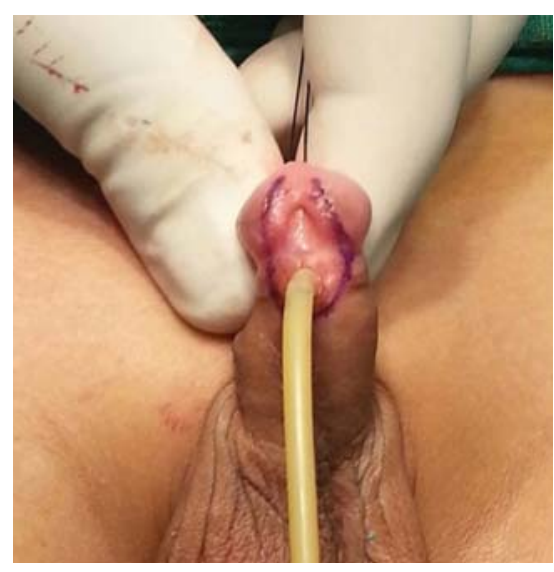

Fig 1: U shape incision over urethral plate

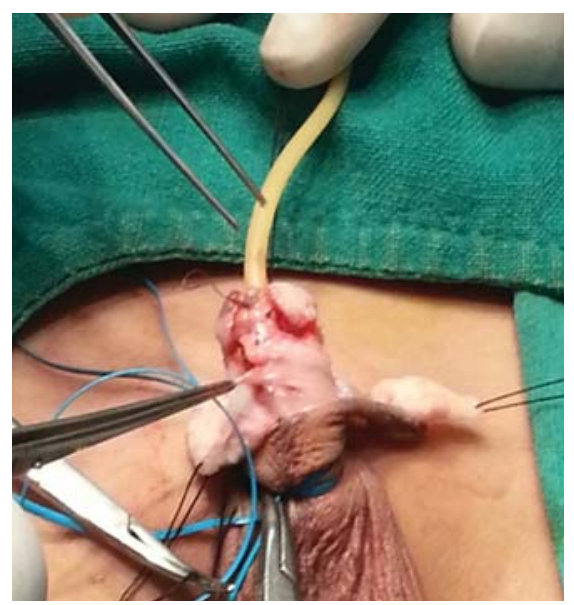

Fig 4: Neourethra coverage by dartos

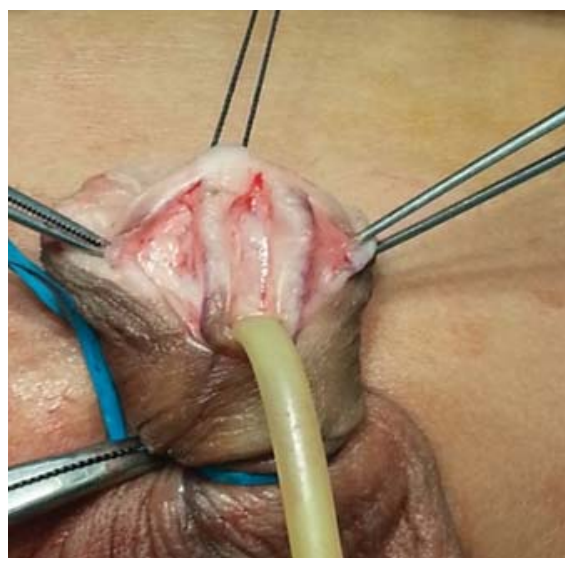

Fig 2: Midline and parallel plate incision

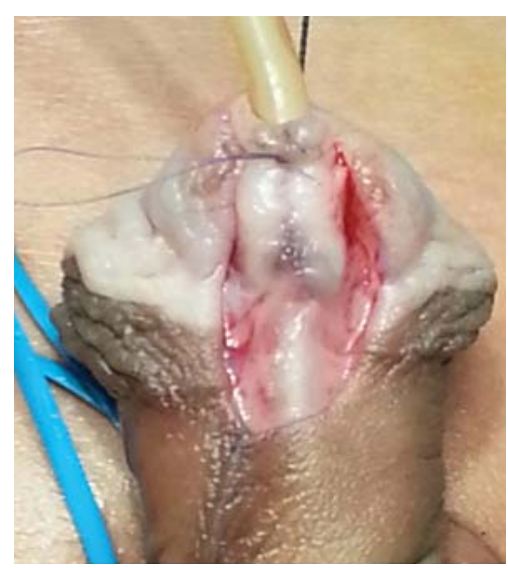

Fig 3: Neourethra (tubularization)

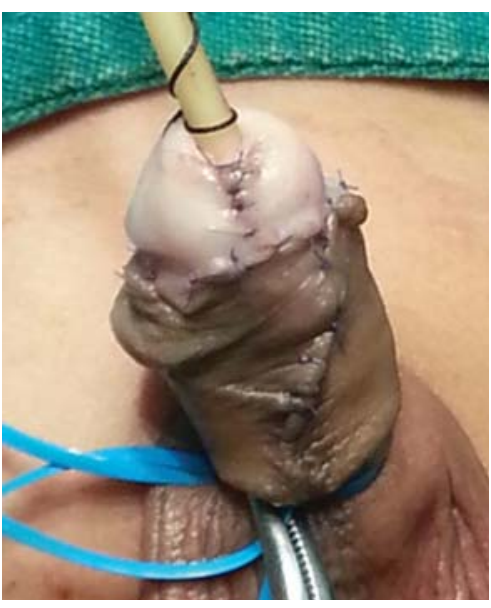

Fig 5: Final repair

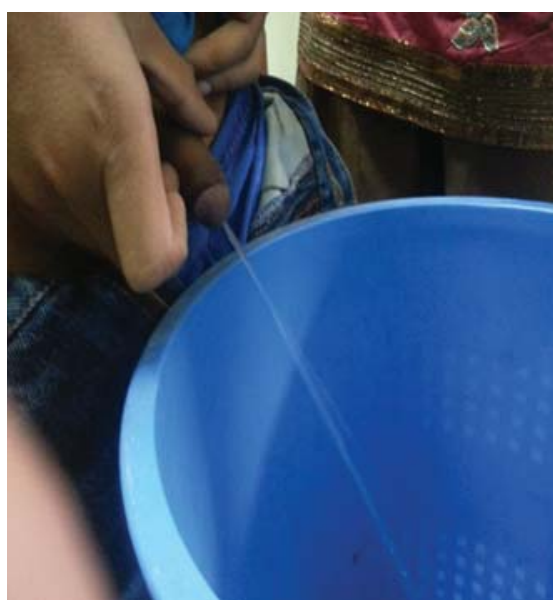

Fig 6: Straight urinary stream

\section{Discussion}

The technique of tubularized incised plate urethroplasty for distal hypospadias described here has several advantages over other procedures. Meatal advancement and glanuloplasty (MAGPY) was developed to correct a meatus which has urinary stream going downward as its demerits. Mathew, onlay and island pedicle flap procedure has also been widely used with minimal complications but the meatus appearing rounded like fish mouth in contrast to slit like of a normal meatus was their disadvantage. Thiersc-duplay procedure leads to glanular meatus and is a two stage surgery as its drawback $^{3,4}$. All drawbacks of these procedures are completely omitted by TIP urethroplasty. The rate of complications like urethrocutaneous fistula, meatal stenosis, ease of surgery and duration is also in favor of TIP urethroplasty.

Rich et al introduced the principle of incising the urethral plate in the midline to improve the cosmetics of a hypospadias repair in $1989^{\circ}$. The goal of hypospadias surgery is a penis that is functionally and cosmetically normal. This is achieved by constructing a straight penis with meatus as close as possible to normal site 
with proper shape to allow a forward directed stream and normal coitus ${ }^{9,10}$.

In 1994 Snodgrass used this concept and extended the incision of the urethral plate from the meatus to the TIP of the glans. It has gained popularity so that most surgeons today prefer doing TIP rather than other procedure for distal hypospadias. TIP has better outcome, less complications and good cosmetic looks. The main advantage of TIP is it is technically easy, gives a normal looking vertical slit like meatus which is not achieved in other procedure ${ }^{10,11,12,13,14}$. Forty three (93.4\%) patients in our series had good looking glans and meatus with straight urinary stream. The other main advantage of TIP is a single stage surgery which helps to reduce multiple exposure of anesthesia to the patient .TIP surgery in terms of surgery duration is also shorter with the time range of $60-80$ minutes in this series.

Although several modifications and refinements have been made urethrocutaneous fistula still remains the main postoperative complications ${ }^{15,16}$. Our fistula rate was 5 (10.86\%). Various study shows frequency of fistula formation after TIP urethroplasty ranges $0.5 \%$ to $16 \%$. Zhou et al had $12.5 \%$ and Ahmad $\mathrm{K}$ noted $11.8 \%$ fistula rate ${ }^{17,18}$. The rate of fistula formation is markedly less in TIP urethroplasty than other procedure. Anwar et al did a comparative study between TIP and Mathieu and found overall results in terms of fistula and cosmesis, TIP is better for distal hypospadias. Similar report by Muhammad et al in their comparative study between TIP and Mathieu recommended TIP as their primary treatment for distal hypospadias ${ }^{19,20}$.

This marked decrease in fistula formation is due to the coverage of neourethra by the subcutaneous vascularised layer of dartos taken from dorsal prepuce and shaft skin. It was mentioned in 2003 by Sozbir and Snodgrass. In our cases we also had used single or double layer in between neourethra and skin coverage. Cheng et al have also suggested a two layer closure of the neourethra to minimize the fistula rate ${ }^{21,22}$.

Some western study shows fistula formation rate less than $2 \%$. It may be due to the development of subspecialty like paediatric urology, paediatric plastic surgery and dedications of surgeons to special field of hypospadias. Our result is also excellent and acceptable in our context where we paediatric surgeon have to deal all sorts of general paediatric and urosurgery cases.

The longitudinal incision on the urethral plate in Snodgrass urethroplasty is an innovation of urethral plate preservation as the plate is not the cause of chordee. This midline incision in urethral plate helps to make a tension free tabularization to form a neourethra of an adequate size. Baskin et all in their histological study of urethral plate found sub mucosal layer of plate is highly vascularized with good nerve supply. This makes the healing of this incision by re-epithelialization with normal tissue but not by scar formation. This property leads to less chance of urethral stricture resulting good urinary stream ${ }^{2,5,8}$. In our series we had only one case of meatal stenosis which was managed by meatotomy.

Tubularized incised plate urethroplasty (TIP) can also be used in redo cases as well as proximal and more severe form of hypospadias. A.M. Kamal et al in their series of tip urethroplasty in redo cases showed an excellent cosmetic and functional result ${ }^{23}$. Chen et al performed TIP in 40 cases of proximal hypospadias and overall complication rate was $17.5 \%{ }^{24}$. Warren Snodgrass and Selcuk Yucel perform TIP in $65 \%$ of all proximal hypospadias with an overall complication rate of $37 \%$. Fistula occurred in 7 out of 35 patients $(20 \%)^{25}$. At our initial stage for proximal and severe form of hypospadias we did stage surgeries with orthoplasty (straightening of penis) as first stage and urethroplasty as second stage. Now we have started doing TIP urethroplasty as single stage surgeries for proximal hyposapdias.

\section{Conclusion}

Tubularized incised plate urethroplasty is a simple, single stage surgery for distal hypospadias. It gives good functional neourethra of normal looking glans and meatus with a low rate of complications like urethrocutaneous fistula, stricture. It is our preferred method of repairing distal and midpenile hypospadias in our institution.

\section{Acknowledgements: Nil \\ Funding: Nil \\ Conflict of Interest: Nil \\ Permission from IRB: Yes}

\section{References}

1. Daulat Khan. Management of hypospadias in children. J Surg Pak (International) 2008;3(2):8284.

2. Laurence S. Baskin, Michele B. Ebbers . Hypospadias: anatomy, etiology and technique. J Pediatr Surg 2006;41:463-72. 
3. Hastie K.J et al. Long term follow up of the MAGPI operations for distal hypospadias. Brit J Urol 1989;63(3):320-2.

4. Steckler R.E. and Zaontz M.R. Stent free ThierschDuplay hypospadias repair with the Snodgrass modifications. J Urol 1997;158:1178-80.

5. Snodgrass W. Tubularized incised plate urethroplasty for distal hypospadias. J Urol 1994;151:464-65.

6. Warent T. Snodgrass. Tubularized incised plate hypospadias repair: indications, technique and complications. Urology 1999;54:6-11.

7. Selami Sozubir and warren Snodgrass. A new algorithm for primary hypospadias repair based on tip urethroplasty. J Pediatr Surg 2003;38(8):115761.

8. Rich MA, Keating MA, Synder HM. Hinging the urethral plate in hypospadias meatoplasty. J Urol 1989;142:1551-3.

9. Al-Saied G, Gamal A. Versatility of tubularized incised plate urethroplasty in the management of different types of hypospadias: 5-year experience. Afr J Paediatr Surg 2009;6(2):88-92.

10. Ruziicka Milicevic, Milan Bojanovic et al. Our experience with tubularized incised plate uretrhoplasty for distal and mid-penile hypospadias. Ada Media Medianae 2003; 42:3537.

11. Hombalkar N.N., Gaurav P.D., Parmar R.R. Snodgrass procedure-Versatile technique for various types of hypospadias repair. JKIMSU 2013;2(2):116-22

12. Mohammed H. Aldabbagh. Evaluation of Snodgrass technique in the management of hypospadias in Heevi hospital. Duhok Med J 2011;5(1):41-46.

13. Firas S Attar. Evaluation of the tubularized incised plate urethroplasty (TIP) for repair of distal hypospadias. Bas J Surg 2009;15:81-85.

14. S. M. Barrack, S.H. Hamdun et al. Tubularized incised plate urethroplasty for distal hypospadias. East African Med J 2001;78(6):327-29.
15. SK Sinha Roy ,K Saha, PK Bhattacharjee, TK Majhi. Short term results of Snodgrass tubularized incised plate urethroplasty in distal and mid penile hypospadias. J Indian Assoc Pediatr Surg 2003;8:226-30.

16. Muhammad Ujair, Munir Ahmad, Mussarat Hussain et al. Frequency of urethrocutaneous fistula following Snodgrass hypospadias repair in children. JPMI 2013;27(1):74-77.

17. Zhou Y, Lu J, Takahashi G. Snodgrass procedure for primary hypospadias repair: Int J Urol 2002; 9:2158.

18. Ahmed K. Snodgrass repair for distal hypospadias: a review of 75 cases. Ann Pediatr Surg 2012;8:124.

19. Anwar-ul-Haq, Nadeem Akhter et al. Comparative study of Mathieu and Snodgrass repair for anterior hypospadias. J Ayub Med Coll Abbottabad 2006;18(2):50-52.

20. Muhammad Shahzad, Saleem et al. Comparative study between tubularized incised plate (Snodgrass) urethroplasty and reverse flap (Mathieu's) repair in distal hypospadias. Ann Pak Inst Med Sci 2012;8(2):96-100.

21. Ahmed M.Aboul, Sherine M. Aboul et al. Modified tabularized incised plate (TIP) hypospadias repair using dartos fascia flap. Egypt J Plast Reconstr Surg 2006;30(2):139-42.

22. Cheng EY, Vemulapalli SN, Kropp BP, Pope JC, Furness PD et al. Snodgrass hypospadias repair with vascularised dartos flap: the perfect repair for virgin case of hypospadias. J Urol 2002;168:17236.

23. A.M. Kamal, S.E. Abou Hashem et al. Tubularized incised plate (TIP) urethroplasty: Extended use in hypospadias re-operation. African J Urol 2005;11 (1): 15-21.

24. Chen SC, Yang SS, Hsieh CH, et al.Tubularized incised plate for mid shaft and proximal hypospadias repair. J Urol 2007;17:698-702.

25. Warren Snodgrass and Selcuk Yucel: Tubularized incised plate urethroplasty for proximal hypospadias. Brit J Urol Int 2002;89-90. 